\title{
Costal cartilage overgrowth does not induce pectus-like deformation in the chest wall of a rat model
}

\author{
VLAD LAURENTIU DAVID ${ }^{1}$, MARIA CORINA STANCIULESCU ${ }^{1}$, FLORIN GEORGE HORHAT $^{2}$, \\ ABHINAV SHARMA ${ }^{3,4}$, NILIMA RAJPAL KUNDNANI ${ }^{5}$, BOGDAN CIORNEI ${ }^{1}$, \\ RAMONA FLORINA STROESCU ${ }^{6}$, MARIUS CALIN POPOIU ${ }^{1}$ and EUGEN SORIN BOIA ${ }^{1}$ \\ Departments of ${ }^{1}$ Pediatric Surgery and Orthopedics, ${ }^{2}$ Microbiology and ${ }^{3}$ Cardiovascular Rehabilitation, \\ 'Victor Babes' University of Medicine and Pharmacy, 300041 Timisoara; ${ }^{4}$ Department of \\ Occupational Medicine, Municipal Emergency University Hospital, 310037 Arad; Departments of \\ ${ }^{5}$ Functional Sciences, Physiology, Centre of Immuno-Physiology and Biotechnologies (CIFBIOTEH) and \\ ${ }^{6}$ Pediatrics, 'Victor Babes' University of Medicine and Pharmacy, 300041 Timisoara, Romania
}

Received May 23, 2021; Accepted December 1, 2021

DOI: $10.3892 /$ etm.2021.11069

\begin{abstract}
Overgrowth of the costal cartilages has been frequently reported to be an etiological factor of chest wall deformities in children. The present study aimed to investigate if induced overgrowth of the costal cartilages could lead to deformation of the chest wall in a rat model. An insulin-like growth factor 1 (IGF1) solution was directly injected under the perichondrium of the last three costal cartilages of 2-week-old rat pups. Two different concentrations, $50 \mu \mathrm{g} / \mathrm{ml}$ (E50) and $100 \mu \mathrm{g} / \mathrm{ml}$ (E100), were applied. This procedure was repeated once per week for 5 consecutive weeks. Subsequently, 14 days after the last injection, all animals were euthanized before the shape of the thoracic cage was assessed, and the diameter was measured. In addition, the last three costal cartilages were dissected before the samples were prepared and examined by light microscopy. Rats that received E100 exhibited larger sagittal and coronal rib cage diameters compared with those in the E50 and control groups. However, no deformation could be observed in the chest wall. Microscopic examinations revealed an anabolic pattern in the E100 group. The present findings suggested that locally administered IGF1 stimulated
\end{abstract}

Correspondence to: Dr Ramona Florina Stroescu, Department of Pediatrics, 'Victor Babes' University of Medicine and Pharmacy, Eftimie Murgu Square 2, 300041 Timisoara, Romania

E-mail: ramona.giurescu@gmail.com

Dr Nilima Rajpal Kundnani, Department of Functional Sciences, Physiology, Centre of Immuno-Physiology and Biotechnologies (CIFBIOTEH), 'Victor Babes' University of Medicine and Pharmacy, Eftimie Murgu Square 2, 300041 Timisoara, Romania E-mail:knilima@umft.ro

Key words: chest wall deformity, pectus excavatum, pectus carinatum, etiology, insulin-like growth factor, costal cartilage, overgrowth cell proliferation and tissue growth in coastal cartilages in a dose-dependent manner in vivo. However, this induced overgrowth of the costal cartilages did not result in the deformation of the chest wall.

\section{Introduction}

Pectus excavatum (PE) and pectus carinatum (PC) are two of the most common malformations of the thoracic cage with an incidence of 0.1-0.8/100 people (1). At present, the etiology of both PE and PC remains poorly understood. A number of studies have previously demonstrated that patients with PE or PC present with various ultrastructural disorders of the costal cartilages (1-3). Among the several underlying causes that have been previously proposed, overgrowth of the costal cartilages has been frequently reported for the development of PE and PC (2). This proposal suggests that the disproportionate growth of the costal cartilages forces the sternum to either bend backwards (in PE) or forwards (in PC) $(3,4)$. Although this hypothesis was postulated $\sim 100$ years ago, to the best of our knowledge, the exact cause of costal cartilage overgrowth remains unknown (3). Previous studies have also presented evidence contradicting this currently accepted theory, by reporting no difference in the lengths of the costal cartilages between patients with PE or PC and healthy individuals $(5,6)$.

Insulin-like growth factor 1 (IGF1) is one of the main anabolic growth factors in human hyaline cartilages (7). Considering that cartilage is a primary target tissue for proteins of the insulin growth factor family (8), IGF1 is the optimal choice to induce the overgrowth of the costal cartilages (8). IGF1 regulates articular cartilage homeostasis and has been extensively used as a promoter of chondrogenesis both in vitro and in vivo (7-10). It has been documented that IGF1 treatment can increase cell proliferation and stimulate chondrocyte synthesis of proteoglycans and type II collagen $(9,10)$.

The present study aimed to investigate if induced overgrowth of the costal cartilages could lead to the deformation of the anterior chest wall in a rat model. The present study aimed 
to demonstrate the effectiveness of IGF1 in an animal model. So, the methods used had two major targets: i) To induce the overgrowth of the costal cartilages in a rat model; and ii) to evaluate if this overgrowth could lead to modifications in the structure or shape of the thoracic wall to mimic PE or PC deformities. Therefore, IGF1 solution (in two different doses) was injected directly under the perichondrium of the lower costal cartilages of rat animal model. The effects of these injections were assessed on macroscopic and microscopic levels.

Several factors have been considered in the design of the present study. It was specifically performed on immature 2-week-old rats to assess the effects of IGF1 on costal cartilage growth. The aim was to mimic the natural progression of the disease and stimulate the overgrowth of the costal cartilage during the growth phase of the animals. In the majority of patients with PE or PC, the deformity in the chest wall has a dynamic, progressive and uneven growth pattern throughout the childhood period (2-4). In young children, deformities are frequently absent or mild and become more evident before worsening during the pre-pubertal growth spurt (2). After adolescence, this deformation typically stabilizes (2). In addition, a similar pattern in the serum levels of IGF1 can also be observed throughout childhood (10).

The second factor considered while designing the present study was the number of cartilages to be injected. In the majority of the patients with PE or PC, the deformation is limited to the lower 3-4 costal cartilages $(2,3)$. The upper costal cartilages and the upper part of the anterior thoracic wall are rarely affected (3). Therefore, the IGF1 solution was only injected into the lower cartilages to closely replicate the natural progression of the disease process.

\section{Materials and methods}

Animals. A total of 40 Sprague-Dawley rats (age, 2 weeks; male, 21; female, 19; mean weight, 21.22 $\pm 1.21 \mathrm{~g}$ ) were randomly selected for the present experiment. The rats were provided by the Animal Facility of 'Pius Branzeu' Center for Laparoscopic Surgery and Microsurgery (Timisoara, Romania). All rats were kept under the same conditions: Constant humidity $(50 \pm 5 \%)$ and temperature $\left(22 \pm 5^{\circ} \mathrm{C}\right)$, a 12 -h light/dark cycle, and food and water ad libitum. The rats were divided into four groups (10 rats/group), with two control and two experimental groups. Ethics approval was obtained from the Ethics Committee of 'Victor Babes' University of Medicine and Pharmacy (Timisoara, Romania) prior to the beginning of the present study. All experiments were performed in accordance with relevant guidelines and regulations. The entire experiment was performed following the guidelines set forth by the Animal Research: Reporting in Vivo Experiments guidelines (11).

No interventions were performed on the rats from the first control group (M0) and they were allowed to grow normally. With the animals on general anesthesia (inhalation, $5 \%$ isoflurane and $\mathrm{O}_{2}$ at $11 / \mathrm{min}$, for induction in the anesthesia chamber, and then $2 \%$ isoflurane and $\mathrm{O}_{2}$ at $11 / \mathrm{min}$ on facemask), the following surgical interventions were performed on rats in the Sham group (M1) and the two experimental groups: An anterior thoracic midline incision was first made, exposing the last three costal cartilages at the junction with the sternum.
Using a 2-ml insulin syringe, $0.02 \mathrm{ml}$ of various solutions were administered bilaterally and directly under the perichondrium of each of the last three costal cartilages in accordance with each of the experimental groups. In the M1 group, $0.02 \mathrm{ml}$ PBS was injected. For rats in the first experimental group (E50), $0.02 \mathrm{ml} \mathrm{IGF1}(50 \mu \mathrm{g} / \mathrm{ml}$; recombinant rat IGF1 protein; cat. no. ab52006; Abcam) solution was injected. For rats in in the second experimental group (E100), $0.02 \mathrm{ml} \mathrm{IGF1} \mathrm{solution}$ (100 $\mu \mathrm{g} / \mathrm{ml}$ ) was injected. The choice of dosage was made based on previous studies involving the intra-articular injection of IGF1 in mice animal models (due to lack of studies using rat models) and IGF1 constructs for osteoarthritic cartilage repair $(8,12)$. This procedure was repeated once a week for 5 consecutive weeks. The weight and the length of the animals included in the present study were measured weekly. Each animal was assessed weekly for PE- or PC-like modifications, which could alter the shape of the thoracic cage.

Measurements. The rats were euthanized by $\mathrm{CO}_{2}(30 \%$; $7 \mathrm{l} / \mathrm{min}$ ) inhalation 2 weeks after the last injection according to American Veterinary Medical Association guidelines (13). For death confirmation, the heartbeat, the spontaneous breathing and the grey discoloration of the nostrils and perioral mucosa at 1, 3 and 5 min were assessed. The rib cage, including the thoracic spine, was surgically isolated, following which the soft tissues and intrathoracic organs were removed. The rib cage was then inspected for pectus-like modifications to the shape of the thorax, the sizes of which were compared among the four groups to assess if PE- or PC-like deformities occurred. Using a ruler, the height of the rib cage (thoracic spine) was measured and recorded, as were the anteroposterior and transverse diameters at the level of the lower thoracic opening.

Sample preparation. Cartilage samples were collected from the last three costal cartilages of each rat. The samples were fixed in $10 \%$ buffered formalin at room temperature for $48 \mathrm{~h}$ and embedded in paraffin. Sections of $3-\mu \mathrm{m}$ thickness were cut from each cartilage sample, dewaxed using xylene at $60^{\circ} \mathrm{C}, 2 \times 5$ min rehydrated in descending alcohol series, and then stained using H\&E (14). The sections were examined using light microscopy at x100 magnification using a Zeiss Scope A1 light microscope (Carl Zeiss AG) equipped with an AxioCam ERc5s digital camera, with one image obtained for each section. The images were processed and analyzed using the NIS-Elements BR v2.30 imaging software (Nikon Corporation). The following morphometric parameters were assessed on each image: i) The density and area of the chondrocytes, ii) the density of the isogenic groups of chondrocytes; iii) the density and area of the chondroblasts; and iv) the density of the isogenic groups of chondroblasts.

Statistical analysis. All statistical analyses were performed using SPSS statistics software v23 (IBM Corp.). The normality of the data was checked using the Shapiro-Wilk test. The original parametric data presented deviation from normality; as a result, the Kruskal-Wallis test was performed, followed by Dunn's post hoc test, to compare the following variables: i) The weight of the animals; ii) the density of the chondrocytes; iii) the area of the chondrocytes; iv) the density of the isogenic groups of chondrocytes; and v) the diameter 
Table I. Weight of the rats during the experiment.

Timepoints

\begin{tabular}{lcccccc} 
Groups & $\begin{array}{c}\text { Baseline, } \\
\mathrm{g}(\mathrm{IQR})\end{array}$ & $\begin{array}{c}\text { Week 1, } \\
\mathrm{g}(\mathrm{IQR})\end{array}$ & $\begin{array}{c}\text { Week 2, } \\
\mathrm{g}(\mathrm{IQR})\end{array}$ & $\begin{array}{c}\text { Week 3, } \\
\mathrm{g}(\mathrm{IQR})\end{array}$ & $\begin{array}{c}\text { Week 4, } \\
\mathrm{g}(\mathrm{IQR})\end{array}$ & $\begin{array}{c}\text { Week 5 (End), } \\
\mathrm{g}(\mathrm{IQR})\end{array}$ \\
\hline M0 & $21.00(19-21)$ & $30.60(30-31)^{\mathrm{a}}$ & $58.00(56-58)^{\mathrm{b}}$ & $109.60(101-111)$ & $139.20(125-146)$ & $212.60(199-227)$ \\
M1 & $21.50(20-23)$ & $30.20(29-31)^{\mathrm{a}}$ & $58.50(57-60)^{\mathrm{b}}$ & $112.70(1-3-122)$ & $143.40(126-156)$ & $250.30(195-295)$ \\
E50 & $21.40(21-22)$ & $29.40(28-30)^{\mathrm{a}}$ & $57.20(56-61)^{\mathrm{b}}$ & $111.40(108-121)$ & $138.20(133-152)$ & $227.50(215-251)$ \\
E100 & $21.00(19-21)$ & $44.80(39-51)$ & $72.20(65-78)$ & $105.60(99-113)$ & $146.80(135-163)$ & $236.00(203-258)$ \\
\hline
\end{tabular}

${ }^{\mathrm{a}} \mathrm{P}<0.001$ vs. E100 at week 1 [E100>M0, M1, E50; H(3)=27.19] and ${ }^{\mathrm{b}} \mathrm{P}<0.001$ vs. E100 at week 2 [E100>M0, M1, E50; H(3)=23.35]. Results are presented as mean (IQR). M0, normal control; M1, sham control; E50, $50 \mu \mathrm{g} /$ insulin-like growth factor 1; E100, $100 \mu \mathrm{g} / \mathrm{ml}$ insulin-like growth factor 1 ; IQR, interquartile range.
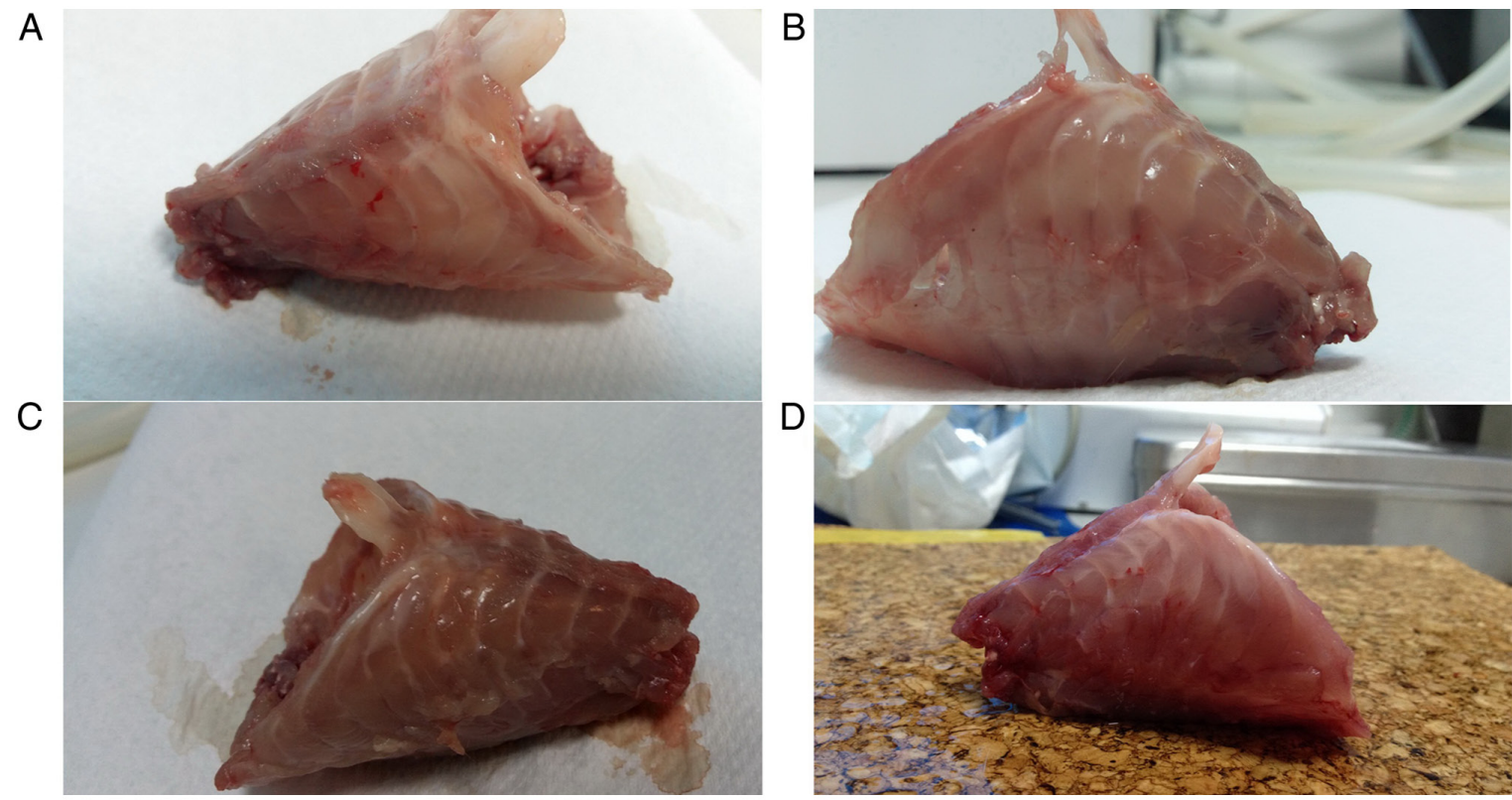

Figure 1. Images of normal-shaped rib cage of rats. The rats either received (A) $100 \mu \mathrm{g} / \mathrm{ml} \mathrm{IGF1,} \mathrm{(B)} 50 \mu \mathrm{g} / \mathrm{ml}$ IGF1, (C) PBS or (D) no injection. IGF1, insulin-like growth factor 1 .

of the thoracic cage. Numerical variables are presented as the median + interquartile range. Pearson's correlation analysis was used to calculate if there was a linear correlation between results of the morphometrical analysis and the diameters of the thoracic cage. $\mathrm{P}<0.05$ was considered to indicate a statistically significant difference.

\section{Results}

Rat model characteristics. The degree of weight gain was comparable during the entire experimental period among the M0, M1 and E50 groups. By contrast, the animals in the E100 group gained significantly more weight compared with those in the other three groups in weeks 1 and $2(\mathrm{P}<0.01$; Table I). There were 21 female and 19 male rats with equal distribution among the groups ( $>0.05$; data not shown). Subsequently for weeks 3-5, the growth rate was normal and was comparable among the four groups. At the end of the experiment, no differences could be noted in terms of weight and body length (data not presented) among the four groups.

Macroscopic assessment of the animal rib cage and measurements. Despite the visible micro-trauma induced by repeated procedures at the site of surgery, none of the four groups developed any deformities synonymous with PE or PC in the rib cage (Fig. 1), meaning clear modification of the shape of the chest wall as previously described in animals or induced in animal models of PE $(15,16)$. All thoracic diameters were found to be similar among the rats in the M0, M1 and E50 groups. However, rats in the E100 groups exhibited significantly larger sagittal and transversal diameters of the rib cage compared with those in the other three groups $(\mathrm{P}<0.002$; Table II).

Light microscopy assessment of the rib cartilages. The results of the morphometric analyses are presented in Table III. A difference was noted in the chondrocyte number 
Table II. Diameters of the rib cage at the end of the experiment.

\begin{tabular}{|c|c|c|c|}
\hline \multirow[b]{2}{*}{ Groups } & \multicolumn{3}{|c|}{ Parameters } \\
\hline & $\begin{array}{l}\text { Axial diameter, } \\
\text { mm (IQR) }\end{array}$ & $\begin{array}{l}\text { Sagittal diameter, } \\
\text { mm (IQR) }\end{array}$ & $\begin{array}{c}\text { Transverse diameter, } \\
\text { mm (IQR) }\end{array}$ \\
\hline M0 & $44.40(41-45)$ & $31.20(30-33)^{\mathrm{a}}$ & $46.80(45-50)^{b}$ \\
\hline M1 & $45.70(41-49)$ & $33.90(28-37)^{\mathrm{a}}$ & $49.00(49-50)^{\mathrm{b}}$ \\
\hline E50 & $46.80(44-49)$ & $31.60(30-33)^{\mathrm{a}}$ & $49.30(48-51)^{b}$ \\
\hline E100 & $45.60(40-50)$ & $40.80(40-41)$ & $59.00(59-62)$ \\
\hline
\end{tabular}

${ }^{\mathrm{a}} \mathrm{P}<0.002$ vs. E100 saggital diameter [E100>M0, M1, E50; H(3)=24.09] and ${ }^{\mathrm{b}} \mathrm{P}<0.001$ vs. E100 transversal diameter [E100>M0, M1, E50; $\mathrm{H}(3)=22.70]$. Results are presented as the mean $(\mathrm{IQR})$. M0, normal control; M1, sham control; E50, $50 \mu \mathrm{g} / \mathrm{ml}$ insulin-like growth factor 1; $\mathrm{E} 100,100 \mu \mathrm{g} / \mathrm{ml}$ insulin-like growth factor 1 ; IQR, interquartile range.

Table III. Results of the morphometry analysis.

\begin{tabular}{|c|c|c|c|c|}
\hline \multirow[b]{2}{*}{ Variables } & \multicolumn{4}{|c|}{ Groups } \\
\hline & M0 & M1 & E50 & E100 \\
\hline $\begin{array}{l}\text { Chondrocytes, } \\
\mathrm{n} / \mu \mathrm{m}^{2}(\mathrm{IQR})\end{array}$ & $25.60(17-39)$ & $25.80(22-30)$ & $21.20(16-30)^{\mathrm{a}}$ & $28.80(25-35)$ \\
\hline $\begin{array}{l}\text { Chondroblasts, } \\
\mathrm{n} / \mu \mathrm{m}^{2}(\mathrm{IQR})\end{array}$ & $21.30(16-34)$ & $21.60(17-27)^{\mathrm{b}}$ & $22.40(17-23)$ & $27.70(20-35)$ \\
\hline $\begin{array}{l}\text { Chondrocyte area, } \\
\mu \mathrm{m}^{2}(\mathrm{IQR})\end{array}$ & $\begin{array}{c}357741.80 \\
(208477-444631)^{\mathrm{c}}\end{array}$ & $\begin{array}{c}396188.80 \\
(328206-446234)^{d}\end{array}$ & $\begin{array}{c}335276.60 \\
(305280-412860)^{\mathrm{e}}\end{array}$ & $\begin{array}{c}130186.80 \\
(25905-36044)\end{array}$ \\
\hline $\begin{array}{l}\text { Chondroblast area, } \\
\mu \mathrm{m}^{2} \text { (IQR) }\end{array}$ & $\begin{array}{c}194357.00 \\
(112437-241008)^{\mathrm{f}}\end{array}$ & $\begin{array}{c}176457.80 \\
(105118-196965)^{\mathrm{f}}\end{array}$ & $\begin{array}{c}159170.20 \\
(144554-173732)^{\mathrm{f}}\end{array}$ & $\begin{array}{c}24172.60 \\
(15366-26566)\end{array}$ \\
\hline $\begin{array}{l}\text { Chondrocyte isogenic } \\
\text { groups, } \mathrm{n} / \mu \mathrm{m}^{2}(\mathrm{IQR})\end{array}$ & $6(4-8)^{g}$ & $6.2(5-8)^{\mathrm{h}}$ & $8.6(5-12)$ & $12.40(8-18)$ \\
\hline $\begin{array}{l}\text { Chondroblast isogenic } \\
\text { groups, } \mathrm{n} / \mu \mathrm{m}^{2} \text { (IQR) }\end{array}$ & $6.6(6-9)^{\mathrm{i}}$ & $6.4(3-8)^{\mathrm{i}}$ & $5.8(4-8)^{\mathrm{i}}$ & 0 \\
\hline
\end{tabular}

${ }^{\mathrm{a}} \mathrm{P}=0.004$ vs. E100 chondrocytes $[\mathrm{E} 100>\mathrm{E} 50 ; \mathrm{H}(3)=8.39] ;{ }^{\mathrm{b}} \mathrm{P}=0.005$ vs. $\mathrm{E} 100$ chondroblasts $\left.[\mathrm{E} 100>\mathrm{M} 1 ; \mathrm{H}(3)=8.08)\right] ;{ }^{\mathrm{c}} \mathrm{P}=0.046$ [M0>E100; $\mathrm{H}(3)=11.31],{ }^{\mathrm{P}} \mathrm{P}=0.001[\mathrm{M} 1>\mathrm{E} 100 ; \mathrm{H}(3)=11.31]$ and ${ }^{\mathrm{e}} \mathrm{P}=0.026$ [E50 $\left.>\mathrm{E} 100 ; \mathrm{H}(3)=11.31\right]$ vs. E100 chondrocyte area; ${ }^{\mathrm{P}}<0.001$ vs. $\mathrm{E} 100$ chondroblast area [E50>E100, M1 $>$ E100, M0>E100; $\mathrm{P}<0.001 ; \mathrm{H}(3)=21.05] ;{ }^{\mathrm{P}} \mathrm{P}=0.003$ [E100 $\left.>\mathrm{M} 0 ; \mathrm{H}(3)=10.84\right]$ and ${ }^{\mathrm{h} P}=0.012$ [E100>M1; $\mathrm{H}(3)=10.84]$ vs. E100 chondrocyte isogenic groups; ${ }^{\mathrm{P}}<0.001$ vs. E100 chondroblast isogenic groups [E50 $>\mathrm{E} 100, \mathrm{M} 1>\mathrm{E} 100, \mathrm{M} 0>\mathrm{E} 100$; $\mathrm{P}<0.001 ; \mathrm{H}(3)=23.27]$. Results are presented as the mean (IQR). M0, normal control; M1, sham control; E50, $50 \mu \mathrm{g} / \mathrm{ml}$ insulin-like growth factor 1; E100, $100 \mu \mathrm{g} / \mathrm{ml}$ insulin-like growth factor 1 ; IQR, interquartile range.

between the E50 and E100 groups and in the chondroblast number between the M1 and E100 groups. While there was no statistical difference found among the first three groups, M0, M1 and E50 ( $\mathrm{P}>0.05)$, the chondrocyte area was larger in the M0, M1 and E50 groups compared with that in the E100 group $(\mathrm{P}<0.05)$. In addition, the chondroblast area was larger in the M0, M1 and E50 groups compared with the E100 group. There were no significant statistical differences for chondroblast area between the M0 and M1, M0 and E50, and M1 and E50 groups (P>0.05). The number of isogenic groups of chondrocytes per image was found to be significantly higher in the E100 group compared with the M1 and M0 groups (Fig. 2; Table III). The number of isogenic groups of chondrocytes per image was similar in the
M0, M1 and E50 groups ( $\mathrm{P}>0.05)$. Similarly, no significant differences were observed regarding the number of isogenic groups of chondrocytes per image between the E50 and E100 groups $(\mathrm{P}>0.05)$. Finally, the number of isogenic groups of chondroblasts per image was similar among the M0, M1 and E50 groups $(\mathrm{P}>0.05)$. In addition, none of the rats from the E100 group presented isogenic groups of chondroblasts. This was significantly different from the other groups $(\mathrm{P}<0.001)$. Pearson correlation coefficient analysis revealed a negative linear correlation in the E100 group between the transverse diameter of the thorax and the number of chondroblasts $(\mathrm{r}=-0.834 ; \mathrm{P}=0.003 ; \mathrm{n}=10)$ and the chondroblast area $(\mathrm{r}=-0.892 ; \mathrm{P}=0.001 ; \mathrm{n}=10)$. No other significant correlations were observed (Table IV). 

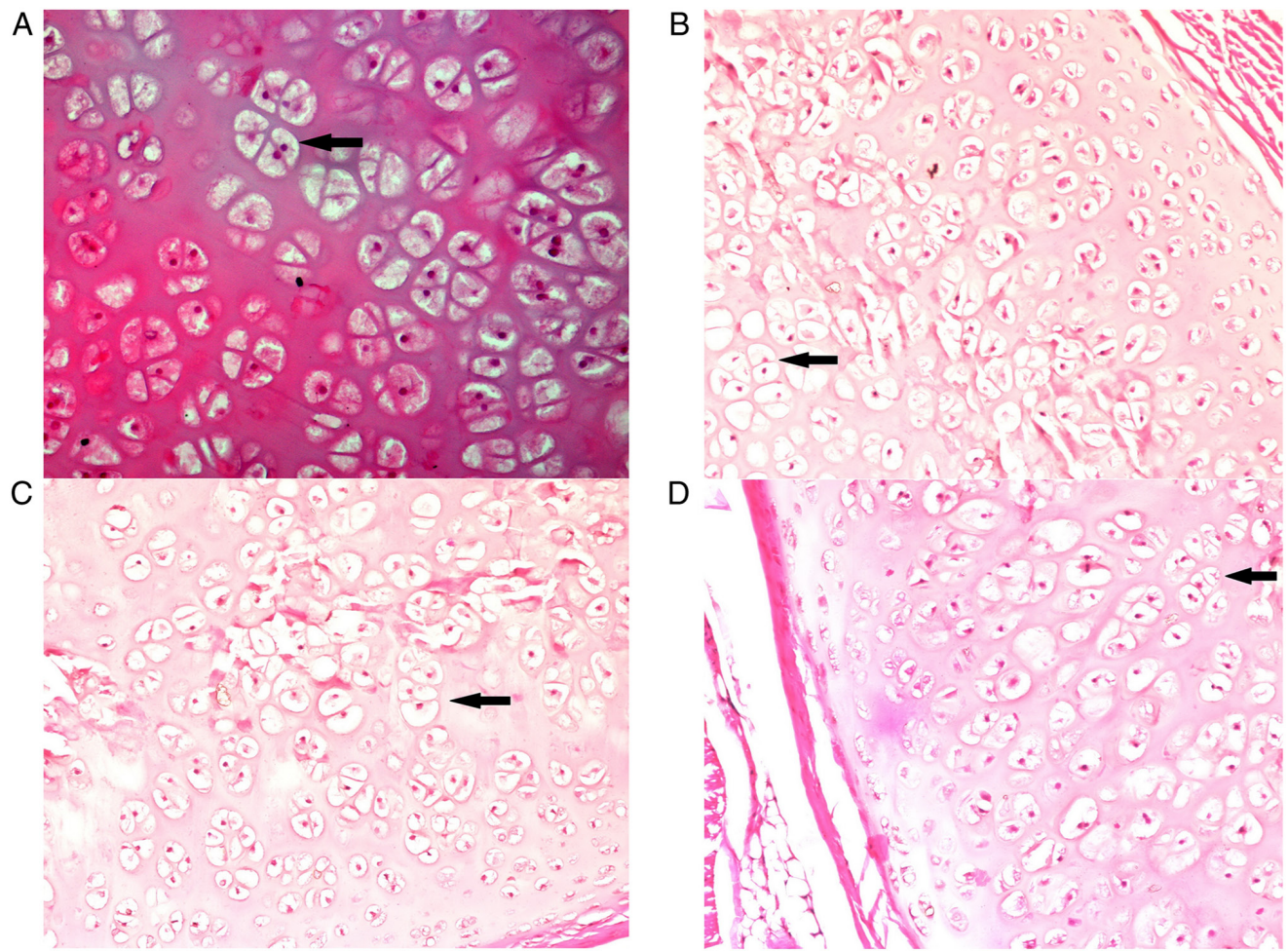

Figure 2. H\&E images of cartilage tissue sections of rats from the four experimental groups. The number of isogenic groups of chondrocytes (arrow) per image (density) was higher in the (A) $100 \mu \mathrm{g} / \mathrm{ml}$ IGF1 group compared with that in the (B) $50 \mu \mathrm{g} / \mathrm{ml}$ IGF1, (C) sham control and (D) normal control groups. Magnification, x20. IGF1, insulin-like growth factor 1.

\section{Discussion}

In the present study, the transverse and sagittal diameters of the rib cages, which are directly influenced by the growth pattern of the costal cartilages and of the adjacent ribs, were found to be greater in rats in the E100 group. This suggested that in these animals, the locally distributed IGF1 interfered with the normal growth pattern of the cartilage by potentiating proliferation further. However, this effect appeared to be dose-dependent, because the diameters of the rib cage in rats in the E50 group were comparable to those in the M0 and M1 groups. In addition, the route of IGF1 administration was considered in the present study, since the aim was to elicit a local response with minimal systemic involvement. The intravenous route was not appropriate, since it could have induced undesirable outcomes through various feedback mechanisms (7). The amplitude of the effects mediated by IGF1 is mainly dependent on two factors: i) Bioavailability of IGF1 in the different biological fluids; and ii) the quantity of viable receptors on the cell surface (8). IGF1 bioavailability is regulated through its binding proteins, especially IGF binding protein 3 (9). However, on a cellular level, the regulatory mechanism remains to be fully elucidated. The main obstacle limiting an effective response to IGF1 is the poor expression of viable receptors on the cell surface, which is genetically determined (8). This hypothesis is supported by reports from various studies performed on different types of cancer, such as ovarian malignant tumors or squamous non-small cell lung carcinoma, which demonstrated that overexpression of IGF1 receptor is key to tumorigenesis and cell proliferation $(9,10)$. The binding of IGF1 to its receptors leads to the activation of an intracellular cascade of signaling and inhibition of further IGF1 and growth hormone (GH) secretion by the cells (9). This serves as a negative feedback mechanism for the GH-IGF1 axis (9). Therefore, the IGF1 solution was administered by direct sub-perichondrium injections. Since no significant differences could be observed in weight and body length among the four groups at the end of the experiment (when the animals exhibit full growth), the systemic effects of IGF1 were concluded to be either minimal or absent.

The present study demonstrated that IGF1 could exert a dose-dependent in vivo chondrogenic effect on the costal cartilages of rats. The direct stimulation of the costal cartilage was found to induce modifications in both the structure and growth pattern of the costal cartilage in the immature rats. The structure of the costal cartilages was under the influence of IGF1, as demonstrated by increased cellularity, area occupied by the cells and isogenic groups of chondrocytes. The anabolic effect of IGF1 on the hyaline cartilage has been reported in several studies $(9,12,17)$. In the present study, the number of chondrocytes and chondroblasts and the area occupied by these cells were higher in the E100 group compared with the control and E50 groups. Additionally, a particular pattern in the isogenic groups was observed, where the number of isogenic groups of chondrocytes were increased in the E100 group compared with the control and E50 groups, while isogenic groups of chondroblasts were entirely absent in the E100 group. This is an indicator that IGF1 can also exert an effect on the differentiation and maturation of the cartilage cells in a dose-dependent manner. The present study demonstrated that the locally distributed IGF1 interfered with the normal growth pattern of the cartilage to stimulate growth. 


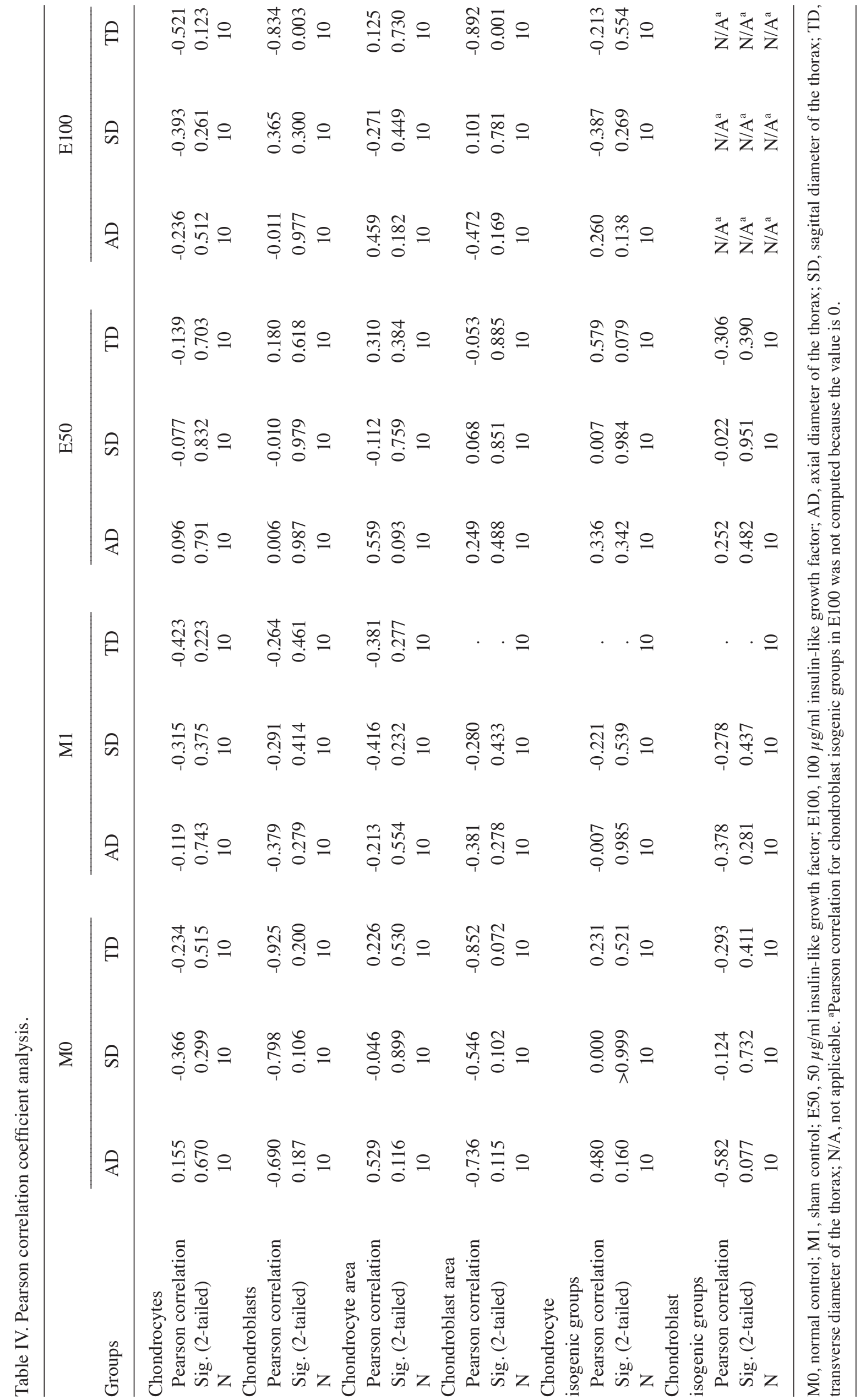


This effect was largely dose-dependent, as the diameters of the rib cage among the E50, M0 and M1 groups were similar and shorter compared with those in the rats in the E100 group. In particular, only the transverse and sagittal diameters of the thorax were longer, suggesting that only the ribs and costal cartilages exposed to high doses IGF1 exhibited rapid growth.

The main purpose of the present experimental study was to identify if induced overgrowth of the costal cartilages led to a pectus-like deformity of the chest wall in experimental animals. Several abnormalities of the physical and structural features of the costal cartilages were previously demonstrated in patients with $\mathrm{PE}$ and $\mathrm{PC}$, including alteration of the collagen network, disturbances in endochondral ossification and costal cartilage growth, low number of cartilage lacunae and cartilage channels, diminished structural strength and decreased water content $(1,18-20)$. These facts led to the conclusion that the deformation of the chest wall in PE or PC was caused by the abnormal growth of the costal cartilages $(1,2)$. However, to this date, to the best of our knowledge, there was no clear explanation as to how these costal cartilage modifications lead to the deformation of the chest wall. The findings of the present study suggested that the pectus-like deformation of the chest wall is independent from the overgrowth of the costal cartilages and adjacent ribs. Though overgrowth of the costal cartilages was observed in E100 animals, neither the retraction nor protraction of the anterior chest wall was observed. Therefore, overgrowth is not the only factor responsible for causing PE or PC. This is contrary to the currently accepted hypothesis concerning PE and PC etiology. The majority of publications in this scientific field, especially previous book chapters or reviews, maintain that the overgrowth of costal cartilages is the definitive cause of PE and PC $(2,3,18)$. However, to the best of our knowledge, no direct scientific evidence could unequivocally prove this hypothesis or definitively show how overgrowth causes deformation in the chest wall. This hypothesis was made based on a number of clinical observation studies and personal opinions dating from $>50$ years ago $(21,22)$. In studies in the last 20 years, overgrowth could not be found in patients with PE or PC $(19,20,23,24)$. In addition, a number of reports demonstrated that the cartilages in patients with PE or PC were not different in length compared with those in healthy individuals, suggesting the lack of excessive growth of the costal cartilages in patients with $\mathrm{PE}$ or PC $(5,6)$. Studies assessing the microscopic structure and the physiology of the costal cartilages from patients with $\mathrm{PE}$ or PC have also been conducted (21-24). Although alterations in the normal structure and function of the costal cartilages were observed, none of these studies were able to demonstrate signs of excessive or greater growth rates in the costal cartilages in patients with PE or PC $(19,20,23,24)$. The results of the present study are consistent with these previous findings $(19,20,23,24)$ and indicate that, although there is evidence of structural and functional abnormalities in the costal cartilages in PE and PC, cartilage overgrowth is unlikely to be the direct cause of these types of chest wall deformities.

In conclusion, the findings of the present study suggested that locally administered IGF1 could stimulate cellular proliferation and multiplication in the costal cartilages of immature rats in vivo. This effect was dose dependent, since for high doses $(100 \mu \mathrm{g} / \mathrm{ml})$, the results were observed at both microscopic (increased number of cells in E100 group) and macroscopic levels (increased sagittal and transverse diameters in E100 group). However, the induced overgrowth of the costal cartilages did not lead to deformations of the anterior chest wall observed in PE or PC in these rats.

\section{Acknowledgements}

Not applicable.

\section{Funding}

No funding was received.

\section{Availability of data and materials}

The datasets used and/or analyzed during the current study are available from the corresponding author on reasonable request.

\section{Authors' contributions}

VLD was responsible for conceptualization, methodology and experiments. MCS, MCP, RFS, FGH, BC, NRK, AS and ESB carried out the experiments. FGH, RFS and NRK were also responsible for formal analysis. AS and NRK carried out reviewing and editing. $\mathrm{BC}$ was responsible for data analysis and visualization. All authors reviewed the manuscript. VLD and $\mathrm{BC}$ confirm the authenticity of all the raw data. All authors have read and approved the final manuscript.

\section{Ethics approval and consent to participate}

Approval was obtained from the Ethics Committee of 'Victor Babes' University of Medicine and Pharmacy (Timisoara, Romania) prior to the commencement (approval no. 14/22.02.2018). All experiments were performed in accordance with relevant guidelines and regulations. The entire experiment was performed in accordance with the guidelines set by the Animal Research: Reporting in Vivo Experiments guidelines.

\section{Patient consent for publication}

Not applicable.

\section{Competing interests}

The authors declare that they have no competing interests.

\section{References}

1. Kurkov AV, Shekhter AB and Paukov VS: Costal cartilage structural and functional changes in children with a funnel or keeled chest. Arkh Patol 79: 57-62, 2017 (In Russian).

2. Nuss D, Obermeyer RJ and Kelly RE Jr: Pectus excavatum from a pediatric surgeon's perspective. Ann Cardiothorac Surg 5: 493-500, 2016.

3. Brochhausen C, Turial S, Müller FK, Schmitt VH, Coerdt W, Wihlm JM, Schier F and Kirkpatrick CJ: Pectus excavatum: History, hypotheses and treatment options. Interact Cardiovasc Thorac Surg 14: 801-806, 2012. 
4. Nicodin A, Boia ES, Popoiu MC, Cozma G, Nicodin G, Badeti R, Trailescu M, Adam O and David VL: Preliminary results after Nuss procedure. Chirurgia (Bucur) 105: 203-210, 2010.

5. David VL, Cerbu S, Haragus H, Popoiu MC, Stanciulescu CM, Cozma G, Burlacu O and Boia ES: Costal cartilages do not overgrow in patients with pectus excavatum. Med Princ Pract 25: 533-538, 2016.

6. Nakaoka T, Uemura S, Yoshida T, Tanimoto T and Miyake H: Overgrowth of costal cartilage is not the etiology of pectus excavatum. J Pediatr Surg 45: 2015-2018, 2010.

7. Dupont J and Holzenberger M: Biology of insulin-like growth factors in development. Birth Defects Res C Embryo Today 69 257-271, 2003.

8. Johns DE and Athanasiou KA: Growth factor effects on costal chondrocytes for tissue engineering fibrocartilage. Cell Tissue Res 333: 439-447, 2008

9. Jones JI and Clemmons DR: Insulin-like growth factors and their binding proteins: Biological actions. Endocr Rev 16: 3-34, 1995.

10. Chitnis MM, Yuen JS, Protheroe AS, Pollak M and Macaulay VM: The type 1 insulin-like growth factor receptor pathway. Clin Cancer Res 14: 6364-6370, 2008.

11. Kilkenny C, Browne W, Cuthill IC, Emerson M and Altman DG; NC3Rs Reporting Guidelines Working Group: Animal research: Reporting in vivo experiments: The ARRIVE guidelines. Br J Pharmacol 160: 1577-1579, 2010.

12. Schmidt MB, Chen EH and Lynch SE: A review of the effects of insulin-like growth factor and platelet derived growth factor on in vivo cartilage healing and repair. Osteoarthritis Cartilage 14: 403-412, 2006.

13. American Veterinary Medical Association (AVMA): AVMA guidelines for the euthanasia of animals. 2020 Edition. AVMA Schaumburg, IL, 2020. https://www.avma.org/sites/default/files/20 20-01/2020-Euthanasia-Final-1-17-20.pdf. Accessed November 10 , 2021.

14. Hackam Lab for Pediatric Surgical, Translational and Regenerative Medicine: Hackam Lab, H\&E staining (regressive method). Johns Hopkins Medicine, Baltimore, MD, 2021. https://www.hopkinsmedicine. org/pediatricsurgery/research/hackam_lab/documents/hopkins hackam_lab_protocols_h_e_regressive_method_staining.pdf Accessed December 2, 2021 .
15. David VL, Ciornei B, Horhat FG, Amaricai E, Horhat DI, Hoinoiu T, Boia ES: Rat Animal Model of Pectus Excavatum. Life-Basel 10: 96, 2020.

16. Rahal SC, Morishin Filho MM, Hatschbach E, Machado VM, Aptekmann KP and Corrêa TP: Pectus excavatum in two littermate dogs. Can Vet J 49: 880-884, 2008.

17. Darling EM and Athanasiou KA: Growth factor impact on articular cartilage subpopulations. Cell Tissue Res 322: 463-473, 2005.

18. Goretsky MJ, Kelly RE Jr, Croitoru D and Nuss D: Chest wall anomalies: Pectus excavatum and pectus carinatum. Adolesc Med Clin 15: 455-471, 2004

19. Feng J, Hu T, Liu W, Zhang S, Tang Y, Chen R, Jiang X and Wei F: The biomechanical, morphologic, and histochemical properties of the costal cartilages in children with pectus excavatum. J Pediatr Surg 36: 1770-1776, 2001.

20. David VL, Izvernariu DA, Popoiu CM, Puiu M and Boia ES: Morphologic, morphometrical and histochemical proprieties of the costal cartilage in children with pectus excavatum. Rom J Morphol Embryol 52: 625-629, 2011

21. Giem RN, Paulsen GA and Dykes J: Pectus deformities. Calif Med 94: 306-309, 1961

22. Lester CW: The etiology and pathogenesis of funnel chest, pigeon breast, and related deformities of the anterior chest wall. J Thorac Surg 34: 1-10, 1957

23. Kurkov AV, Paukov VS, Fayzullin AL and Shekhter AB: Costal cartilage changes in children with pectus excavatum and pectus carinatum. Arkh Patol 80: 8-15, 2018 (In Russian).

24. Tocchioni F, Ghionzoli M, Calosi L, Guasti D, Romagnoli P and Messineo A: Rib cartilage characterization in patients affected by pectus excavatum. Anat Rec (Hoboken) 296: 1813-1820, 2013.

This work is licensed under a Creative Commons Attribution-NonCommercial-NoDerivatives 4.0 International (CC BY-NC-ND 4.0) License. 